Supporting Information for:

\title{
Multi-Iron Wells-Dawson Heteropolytungstates. Electrochemical Probing of Siderophoric Behavior in Sandwich-Type Complexes
}

\author{
Bineta Keita $^{\dagger}$, Israel Martyr Mbomekalle ${ }^{\dagger}$, Louis Nadjo ${ }^{*, \dagger}$, Travis M. Anderson ${ }^{\ddagger}$, and \\ Craig L. Hill ${ }^{*, \ddagger}$ \\ ${ }^{\dagger}$ Laboratoire de Chimie Physique, UMR 8000, CNRS, Université Paris-Sud, Bâtiment \\ 420, 91405 Orsay Cedex, France \\ ${ }^{\ddagger}$ Department of Chemistry, Emory University, Atlanta, Georgia, 30322
}

Figure S1. Cyclic voltammograms of the complex Fe4As4 $\left(2 \times 10^{-4} \mathrm{M}\right)$ before and after electrolysis of Fe centers.

Figure S2. Comparison of the cyclic voltammograms of $2 \times 10^{-4} \mathrm{M}$ Fe4X4 (X = P or As) in a $0.1 \mathrm{M} \mathrm{NaCl}+\mathrm{HCl}(\mathrm{pH} 3)$ buffer solution.

Figure S3. Evolution of the cyclic voltammogram observed for $2 \times 10^{-4} \mathrm{M}$ Fe4As4 with the nature of the anion present in the supporting electrolyte.

Figure S4. Evolution of the cyclic voltammograms observed for a $2 \times 10^{-4} \mathrm{M}$ solution of Fe4P4 as a function of the $\mathrm{pH}$ of the supporting electrolyte.

Figure S5. Evolution of the cyclic voltammograms observed for a $2 \times 10^{-4} \mathrm{M}$ solution of Fe4As4 as a function of the $\mathrm{pH}$ of the supporting electrolyte.

Figure S6. Cyclic voltammograms of $2 \times 10^{-4} \mathrm{M}$ Fe3X2 (X = P or As) under various conditions. 


\section{Captions for the SI}

Figure S1. Cyclic voltammograms of the complex Fe4As4 $\left(2 \times 10^{-4} \mathrm{M}\right)$. The scan rate was $2 \mathrm{mV} \mathrm{s}^{-1}$ and the reference electrode was SCE. All measurements were performed in a $2 \mathrm{M} \mathrm{NaCl}+\mathrm{HCl}(\mathrm{pH} 3)$ buffer solution. The working electrode was a glassy carbon plate $\left(4 \mathrm{~cm}^{2}\right)$ which was used for the exhaustive controlled potential reduction of the $\mathrm{Fe}$ (III) centers within Fe4As4, followed by an attempt at their regeneration. The cyclic voltammogram before electrolysis is marked 1 while the cyclic voltammogram after the forward and backward electrolyses is indicated by a 2 . See the text for more details.

Figure S2. Comparison of the cyclic voltammograms of $2 \times 10^{-4} \mathrm{M}$ Fe4X4 (X = P or As) in a $0.1 \mathrm{M} \mathrm{NaCl}+\mathrm{HCl}(\mathrm{pH} 3)$ buffer solution. The scan rate was $10 \mathrm{mV} \mathrm{s}^{-1}$, the working electrode was glassy carbon, and the reference electrode was SCE.

Figure S3. Evolution of the cyclic voltammogram observed for $2 \times 10^{-4} \mathrm{M}$ Fe4As4 with the nature of the anion present in the supporting electrolyte. The scan rate was $10 \mathrm{mV}$ $\mathrm{s}^{-1}$, the working electrode was glassy carbon, and the reference electrode was SCE. The arrow indicates the free Fe(II) oxidation. The $\mathrm{pH} 3$ buffer solution was composed of 0.4 $\mathrm{M} \mathrm{NaClO}_{4}+\mathrm{HClO}_{4}$ (solid line) or $0.4 \mathrm{M} \mathrm{NaH}_{2} \mathrm{PO}_{4}+\mathrm{H}_{3} \mathrm{PO}_{4}$ (dotted line).

Figure S4. Evolution of the cyclic voltammograms observed for a $2 \times 10^{-4} \mathrm{M}$ solution of Fe4P4 as a function of the $\mathrm{pH}$ of the supporting electrolyte. The scan rate was $10 \mathrm{mV} \cdot \mathrm{s}^{-1}$, the working electrode was glassy carbon, and the reference electrode was SCE. (A) The solid line represents solutions prepared from $2 \mathrm{M}$ $\mathrm{NaCl}+\mathrm{HCl}(\mathrm{pH} 2)$, and the dotted line represents solutions prepared from 2 $\mathrm{M} \mathrm{NaCl}+\mathrm{HCl}(\mathrm{pH} 3) ;(B)$ The solid line represents solutions prepared from 2 
$\mathrm{M} \mathrm{NaCl}+\mathrm{HCl}(\mathrm{pH} 3)$, and the dotted line represents solutions prepared from $2 \mathrm{M} \mathrm{NaCl}+0.1 \mathrm{M} \mathrm{CH} 3 \mathrm{COONa}+\mathrm{CH} 3 \mathrm{COOH}(\mathrm{pH} 4)$.

Figure S5. Evolution of the cyclic voltammograms observed for a $2 \times 10^{-4} \mathrm{M}$ solution of Fe4As4 as a function of the $\mathrm{pH}$ of the supporting electrolyte. The scan rate was $10 \mathrm{mV}$ $\mathrm{S}^{-1}$, the working electrode was glassy carbon, and the reference electrode was SCE. (A) The buffer soluton was $2 \mathrm{M} \mathrm{NaCl}+\mathrm{HCl}$, pH 2 (solid line) or $2 \mathrm{M} \mathrm{NaCl}+\mathrm{HCl}, \mathrm{pH} 3$ (dotted line). (B) The buffer solution was $2 \mathrm{M} \mathrm{NaCl}+\mathrm{HCl}, \mathrm{pH} 3$ (solid line) or $2 \mathrm{M} \mathrm{NaCl}$ $+0.1 \mathrm{M} \mathrm{CH}_{3} \mathrm{COONa}+\mathrm{CH}_{3} \mathrm{COOH}, \mathrm{pH} 4$ (dotted line). Note that the cyclic voltammograms for Fe4As4 display similar behavior to those of Fe4P4 (Figure SI4).

Figure S6. Cyclic voltammograms of $2 \times 10^{-4} \mathrm{M}$ Fe3X2 (X = P or As) under various conditions. The scan rate was $10 \mathrm{mV} \mathrm{s}^{-1}$, and the reference electrode was SCE. (A) Cyclic voltammogram observed after the exhaustive reduction of the $\mathrm{Fe}$ (III) centers in Fe3X2, followed by an attempt at their regeneration in a pH 3 medium $(2 \mathrm{M} \mathrm{NaCl}+\mathrm{HCl})$. A working electrode composed of a glassy carbon plate $\left(4 \mathrm{~cm}^{2}\right)$ was used for exhaustive controlled potential electrolyses. (B) A comparison of the cyclic voltammograms of Fe3X2 $(\mathrm{X}=\mathrm{P}$ or $\mathrm{As})$ in a pH 5 medium $\left(2 \mathrm{M} \mathrm{NaCl}+0.1 \mathrm{M} \mathrm{CH}_{3} \mathrm{COONa}+\mathrm{CH}_{3} \mathrm{COOH}\right)$. The working electrode was glassy carbon ( $3 \mathrm{~mm}$ diameter). 


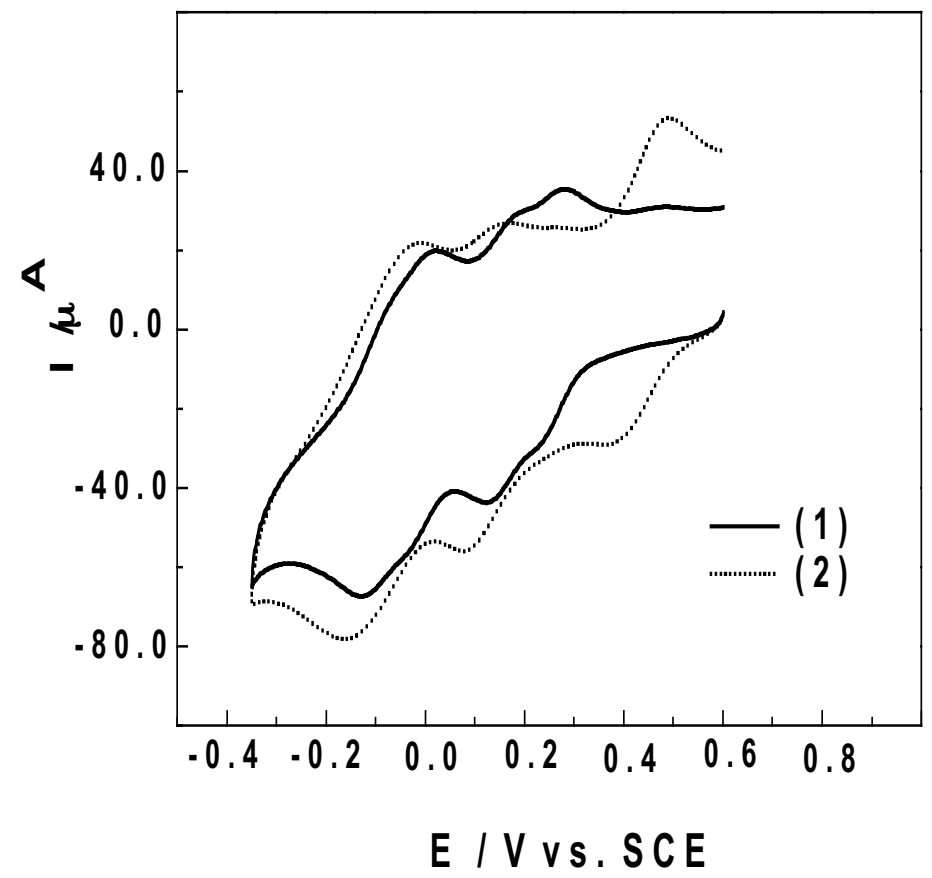

Figure S1 


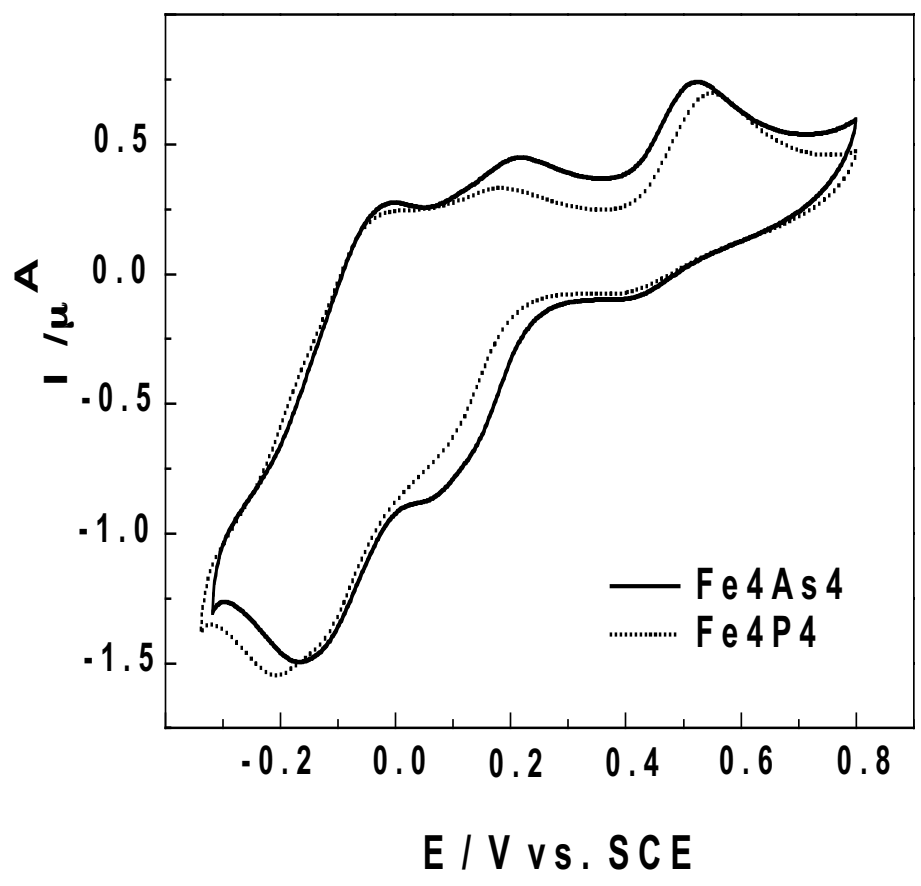

Figure S2 


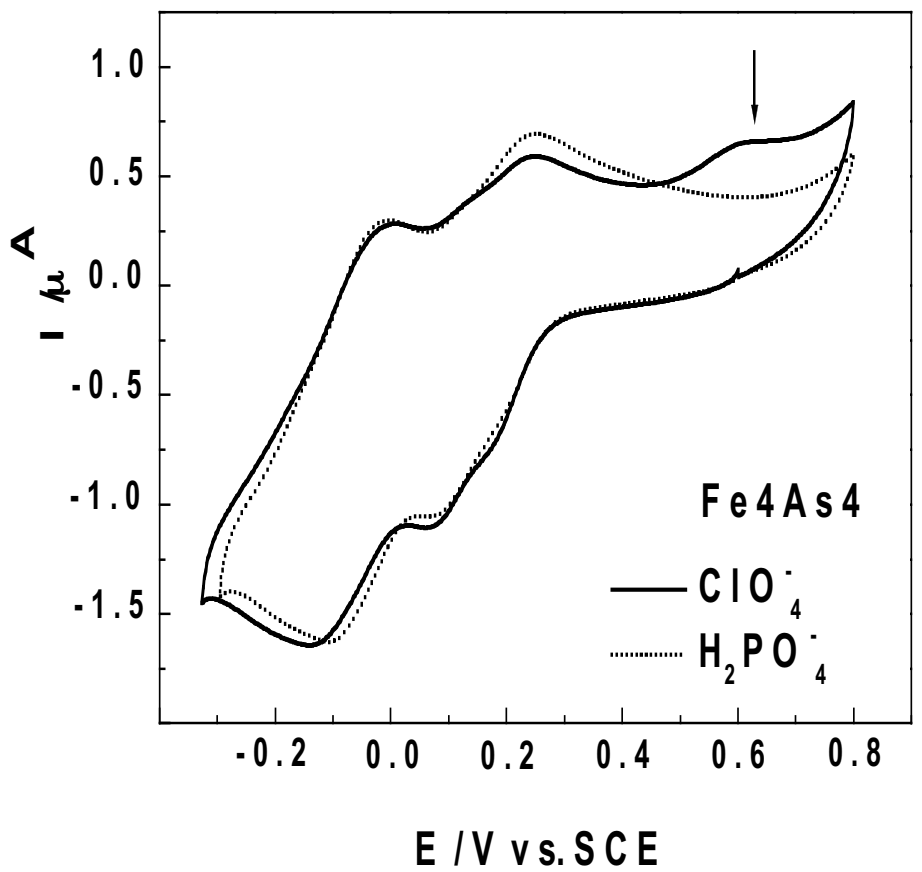

Figure S3 

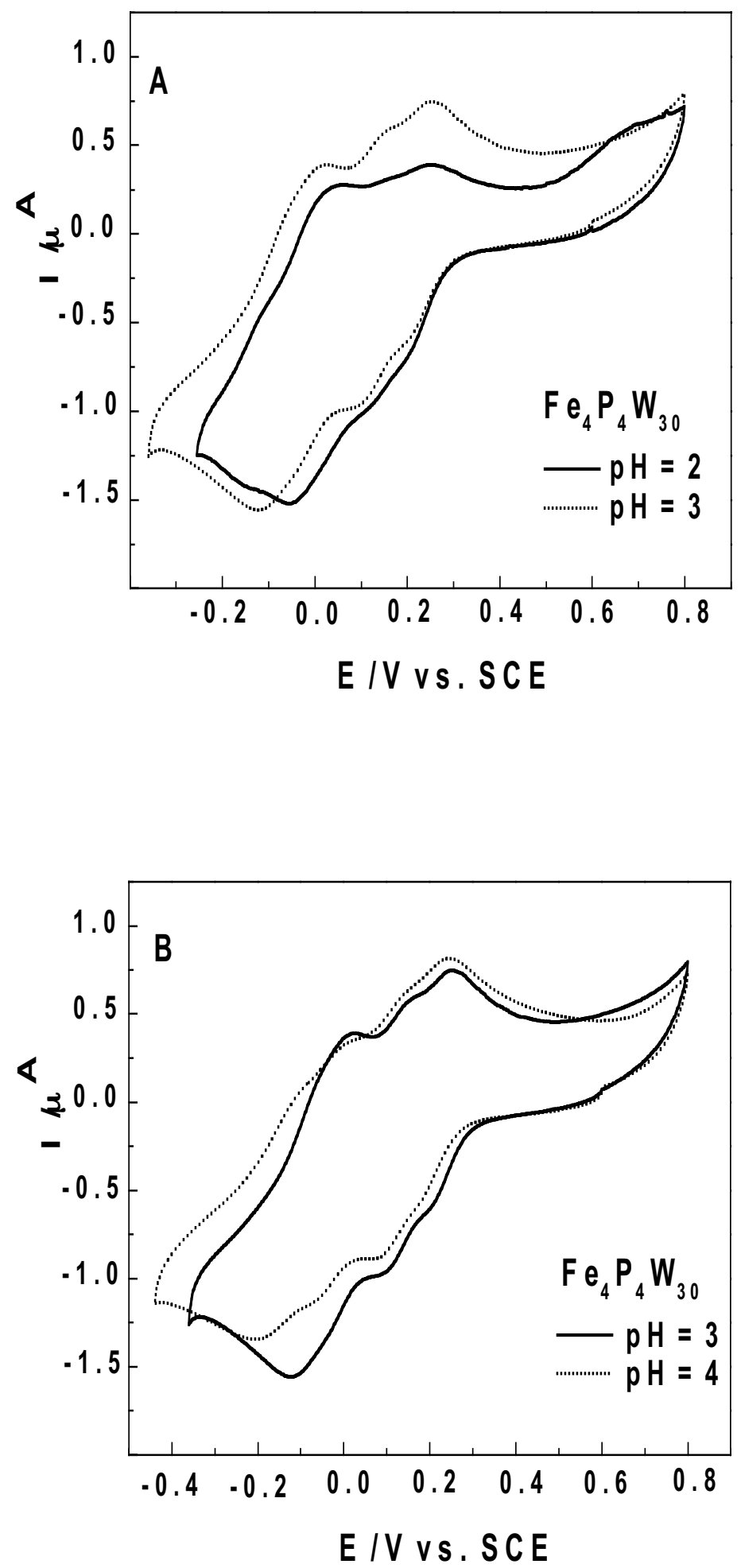

Figure S4 

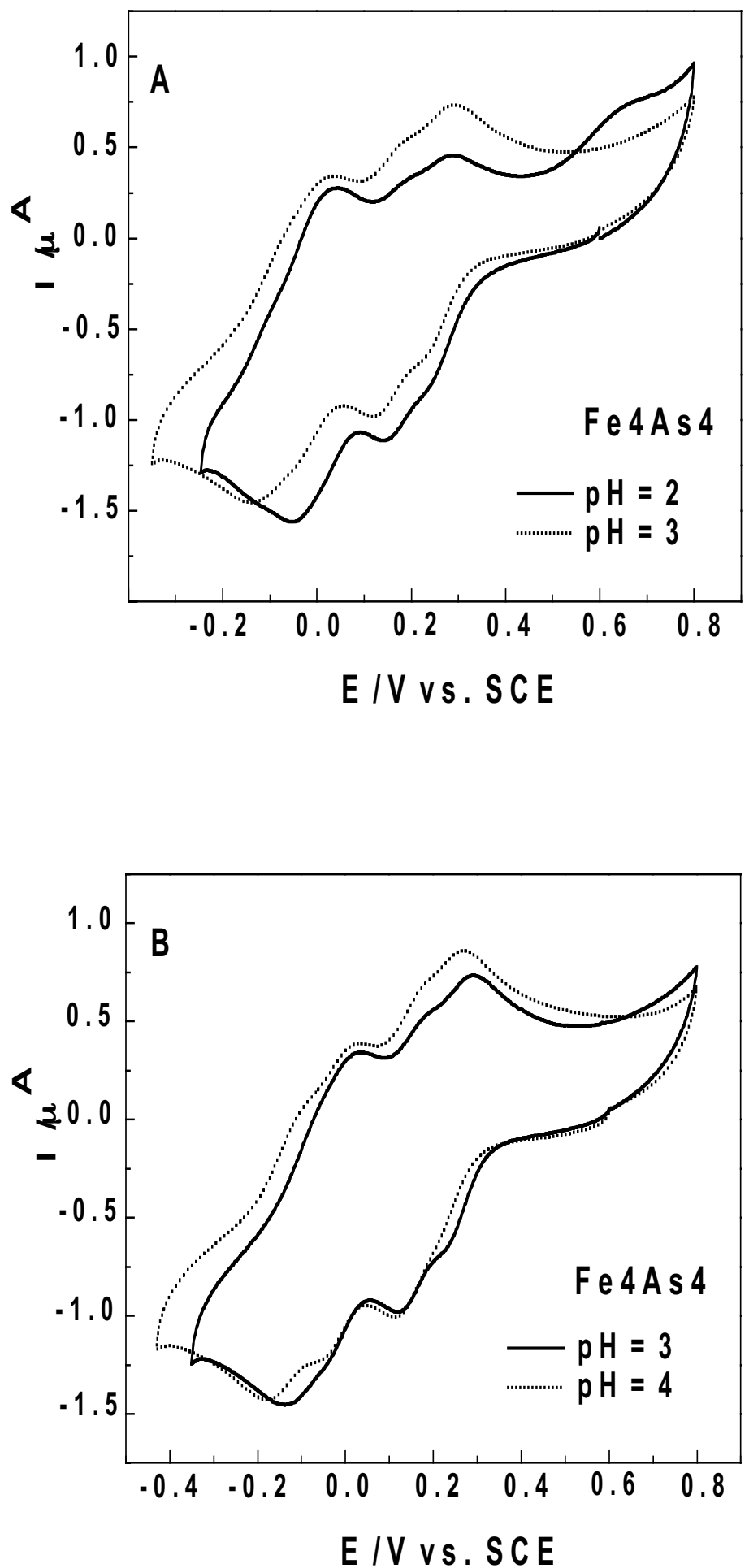

Figure S5 

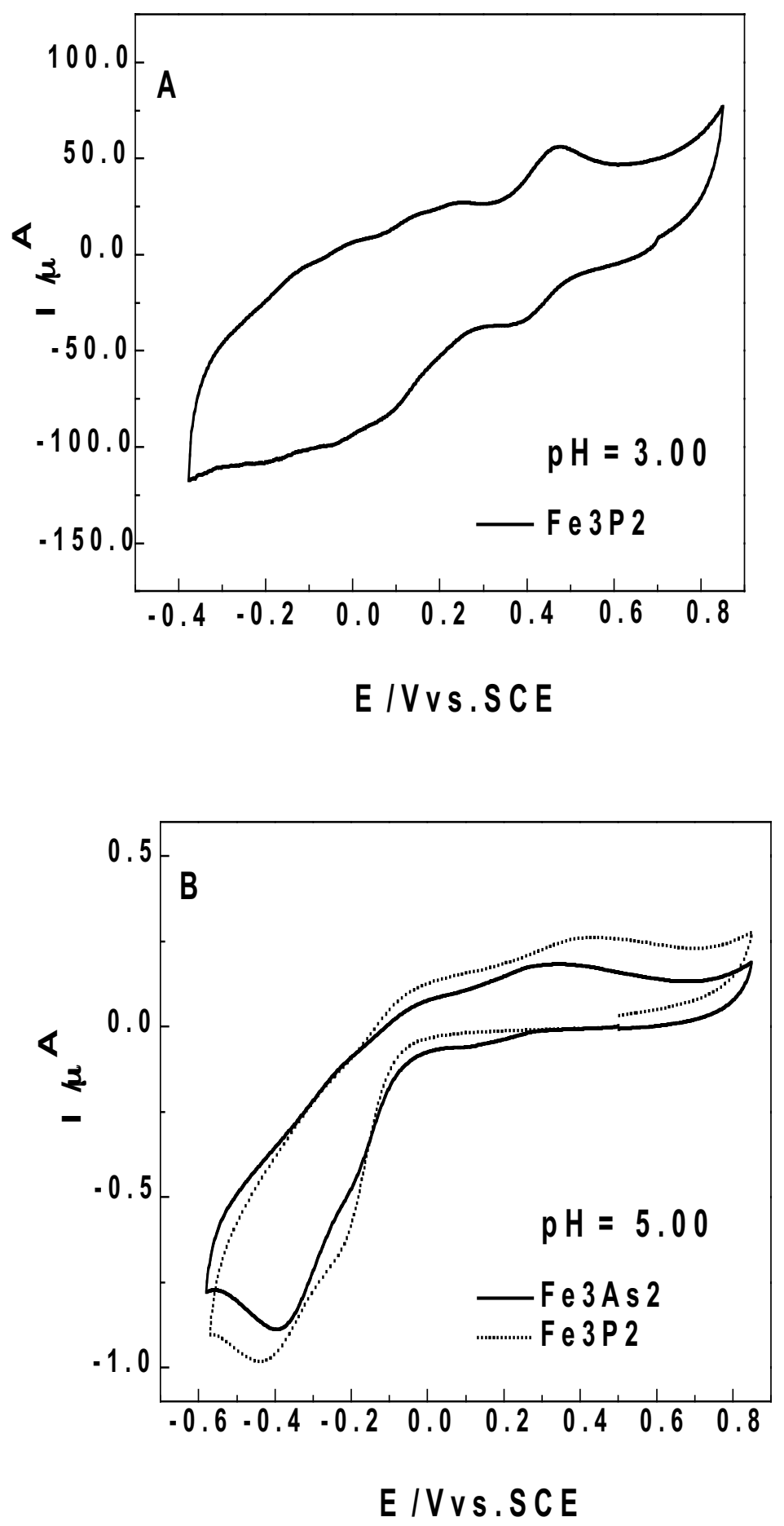

Figure S6 